Pre-print copy of the article:

Bova, A., \& Arcidiacono, F. (2015). Beyond Conflicts: Origin and Types of Issues Leading to Argumentative Discussions

during Family Mealtimes. Journal of Language Aggression and Conflict, 3(2).

\title{
Beyond Conflicts
}

Origin and Types of Issues Leading to Argumentative Discussions during Family Mealtimes

Antonio Bova and Francesco Arcidiacono

This paper sets out to investigate the issues leading parents to engage in argumentative discussions with their children during mealtimes. Within a data corpus of 30 video-recorded meals of 10 middle to uppermiddle-class Swiss and Italian families with a high socio-cultural level, 107 argumentative discussions between parents and children aged from 3 to 9 years old were selected. The approach for the analysis is based on the pragma-dialectical ideal model of a critical discussion. The results show that family argumentative discussions unfold around issues that are generated both by parental prescriptions and by children's requests. The parental prescriptions largely concern context-bound activities such as having to eat a certain food or the teaching of correct table manners. The issues triggered by children's requests refer to a wide range of activities, mainly related to the activity of mealtimes, but also related to the children's behavior outside the family context. These results indicate that argumentative interactions between parents and children are not mere conflictual episodes that must be avoided, but they essentially have a broader educational function.

Keywords: parent-child conflicts, prescriptions, requests, argumentation, mealtimes

\section{Introduction}

Mealtimes is the term used to describe all meals consumed during the day. In many cultures, meals include breakfast, lunch, and an evening meal, referred to colloquially as dinner or tea. Research on mealtime practices, however, is usually concerned with lunchtime and dinnertime, which represent privileged moments to investigate how family members interact, since they can bring all family members together daily (Blum-Kulka 1994; Fiese et al. 2006; Larson et al. 2006; Ochs and Shohet 2006; Pan et al. 2000).

In the present study, we observe mealtime family interactions as key sites to focus on argumentative and conflictual discussions between parents and children. The choice of this topic is certainly not random. The main reason is that argumentative discussions and conflicts are strictly interrelated. We shall immediately delineate the connection as well as the differences between these two notions. Through a fine-grained semantic analysis, Greco Morasso (2008) has indicated two fundamental meanings of the notion of conflict: 1) as an interpersonal hostility between two or more people; and 2) as a propositional incompatibility. According to this author, these two states of affairs are significantly interrelated, because the latter tends to generate the former whenever the incompatible positions are embodied by any parties who feel personally questioned. On the other hand, as suggested by van Eemeren and Grootendorst (2004), argumentative discussions occur when there is a difference of opinion between two (or more) parties and at least one of the parties puts forward an argument in support of his/her standpoint. Therefore, the aspect that more clearly distinguishes an argumentative discussion from a conflict is that in the former, at least one of the parties has shown interest in resolving the difference of opinion in his/her own favor, whilst in the latter, instead, none of the parties shows the willingness to resolve the difference of opinion. However, it is important to stress that both argumentative discussions and conflicts are characterized by a difference of opinion between two or more parties. In our study, 
Pre-print copy of the article:

Bova, A., \& Arcidiacono, F. (2015). Beyond Conflicts: Origin and Types of Issues Leading to Argumentative Discussions during Family Mealtimes. Journal of Language Aggression and Conflict, 3(2).

conflicts will therefore be considered in terms of discursive sequences in which a difference of opinion leads to engagement in argumentative discussions.

In particular, the present paper sets out to investigate the issues that lead parents to engage in argumentative discussions with their children during mealtimes. The research question that we aim to answer is the following: "When parents enter in argumentative discussions with their children during mealtimes, which types of issues lead them to engage in conflict in order to socialize children to appropriate family manners and values?" To achieve this goal, a corpus of argumentative discussions between parents and children aged from 3 to 9 years old will be analyzed.

The approach adopted for the analysis is the pragma-dialectical model of a critical discussion (van Eemeren and Grootendorst 1992, 2004) that proposes an ideal definition of argumentation developed according to the standard of reasonableness: an argumentative discussion starts when the speaker advances his/her standpoint, and the listener casts doubts upon it, or directly attacks the standpoint. Accordingly, confrontation, in which disagreement regarding a certain standpoint is externalized in a discursive exchange or anticipated by the speaker, is a necessary condition for an argumentative discussion to occur. The pragma-dialectical ideal model of a critical discussion spells out four stages that are necessary for a dialectical resolution of differences of opinion between a protagonist that advances and sustains a standpoint and an antagonist that assesses it critically: at the confrontation stage, it is established that there is a dispute. A standpoint is advanced and questioned; at the opening stage, the decision is made to attempt to resolve the dispute by means of a regulated argumentative discussion. One party takes the role of protagonist, and the other party takes the role of antagonist; at the argumentation stage, the protagonist defends his/her standpoint and the antagonist elicits further argumentation from $\mathrm{him} / \mathrm{her}$ if he/she has further doubts; at the concluding stage, it is established whether the dispute has been resolved on account of the standpoint or the doubt concerning the standpoint having been retracted. This model particularly fits our study, and more generally, the study of argumentative interactions occurring in ordinary, not institutionalized, contexts such as family mealtime conversations, because it describes how argumentative discourse would be structured when aimed at resolving differences of opinion.

The article is organized as follows: in the first part, a concise review of the most relevant literature on family argumentative and conflictual discussions is presented and critically discussed. Afterwards, we will describe the methodology that our study is based on. In the last part of the paper, we will present and discuss the results obtained from the analysis, as well as the conclusions drawn in terms of implications for language and educational socialization of children.

\section{Argumentative and conflictual discussions in the family context}

Over the last two decades, the relevance of argumentative interactions between parents and children has been rapidly emerging in family studies. A significant contribution is represented by the research on language socialization at mealtimes carried out by Blum-Kulka $(1993,1997,2008)$ within American and Jewish families; by Ochs and colleagues (Ochs and Kremer-Sadlik 2013; Ochs et al. 1996; Ochs and Schieffelin 2011; Ochs and Taylor 1992) within American families; and by Pontecorvo and colleagues (Arcidiacono et al. 2009; Pontecorvo and Arcidiacono 2007, 2010; Pontecorvo and Fasulo 1997; Pontecorvo et al. 2001) within Italian families. These authors have deeply investigated the cultural patterns for parent-child relationships and the dynamics of pragmatic socialization of young children, highlighting the relevance of mealtimes as sites to observe how behaviors and attitudes of family members are put into doubt. Taken together, these works have shown that argumentative discussions at mealtimes can favor not only the language socialization of young children, but also their socialization to practices, values, and rules typical of their own family and culture. 
Pre-print copy of the article:

Bova, A., \& Arcidiacono, F. (2015). Beyond Conflicts: Origin and Types of Issues Leading to Argumentative Discussions during Family Mealtimes. Journal of Language Aggression and Conflict, 3(2).

Family interactions can be both playful and serious (Goodwin M. H. 2007), participants can use language to laminate frames, creating and maintaining multiple settings simultaneously or transforming them in quick succession. For this reason, argumentative discussions at mealtimes can be considered as moments where parents and children frame interactions around their everyday lives in order to accomplish different tasks. The variety of possible scenarios that parents and children build during their interactions speaks in favor of specific attention to the nature of argumentative exchanges at mealtimes among family members. Existing research on argumentation in the family context is mainly focused on the structure and linguistic elements that characterize discussions between parents and children. Much attention is devoted to investigating the strategies adopted by family members in order to resolve a difference of opinion in their own favor. For example, Bova and Arcidiacono (2014a) have shown that during food-related argumentative discussions, parents in most cases put forward activity-bound arguments, such as the arguments of quality and quantity of food to convince their children to eat (or not to eat more), adapting their language to the child's level of understanding. Similar results can be found in studies on eating practices within family mealtimes by Wiggins and her colleagues (Laurier and Wiggins 2011; Wiggins 2013). Other studies have underlined how disagreements in conversation can be shaped in ways that are confrontational, and appear to sustain and promote conflict with one another, or to shift out or away from an argumentative frame (Tannen 2006; Gordon 2008).

The observation of conversations during mealtimes proved to be activities that are also essential for investigating the argumentative strategies used by children to oppose their parents' argumentation. For example, Brumark (2008) has observed that children aged 12-14 years use arguments that last longer and require more exchanges to be resolved, whereas children aged 7-10 years use shorter arguments that are about the immediate context. Hester and Hester (2010) showed that children are able to use both contextbound and cultural resources to produce their arguments. In a recent work, Bova (forthcoming) observed that in their argumentation, children refer to an adult as a source of expert opinion, and not to another child. According to the author, the actual effectiveness of this type of argument - that he has called argument from adult-expert opinion - depends on how strongly the endoxa, i.e., the premises that the argument is based on, are shared by parents and children ${ }^{1}$. From a developmental psychology perspective, Slomkowski and Dunn (1992) also show that children most often use self-oriented arguments, i.e., talking about themselves, while parents generally use other-oriented arguments, i.e., arguments that refer to children and not to themselves.

Previously, less attention has been paid to understand situations in which parents engage in an argumentative discussion with their children through conflicts, verbal aggression, and different relational dynamics that affect other interactions. In this regard, Tafoya and Hamilton (2012) have shown how conflictual parent-child relationships also influence communication patterns between siblings. In a study by Arcidiacono and Pontecorvo (2009), an analysis of verbal conflicts in a family context has shown the role of the turn-by-turn details of conflict talk as situated interaction, the main aspects of the linguistic choices speakers make in designing and delivering their utterances, and the role of the contextual aspects such as the participants' social relationship, and age for the production and interpretation of talk. Other works concerning the role of conflict in language exchanges have shown the relevance of investigating children's positions and roles in conversational storytelling performances - see for example the study of Norrick (2013), where recipients and co-tellers may display antagonism toward the primary teller, including contradiction, correction - the importance of identity and face in conflict resolution (Bousfield 2013), and the role of irony in decreasing the strength of counter-standpoints in argumentation (Arcidiacono and Bova 2011). As family members can acquire, through conflicts, social knowledge of rules (Hartup and Laursen 1993) and cultural socialization (Farris 2000; Kyratzis and Guo 2001), argumentative discussions are key sites to analyse how parents and children make valuable contributions to structure family interactions. Researchers from outside of the speech act theory perspective seem to concur with the idea that an argument is broader that a single disagreement act. In fact, as suggested by 
Pre-print copy of the article:

Bova, A., \& Arcidiacono, F. (2015). Beyond Conflicts: Origin and Types of Issues Leading to Argumentative Discussions during Family Mealtimes. Journal of Language Aggression and Conflict, 3(2).

Muntigl and Turnbull (1998), argumentative discussions consist of "the conversational interactivity of making claims, disagreeing with claims, countering disagreements and the process by which such disagreements arise, are dealt with, and resolved" (p. 225). Looking at the discursive sequences in which family members engage in argumentative discussions is thus crucial.

Although this paper is not primarily concerned with producing a comprehensive definition of conflict (in this regard see Nelson 2001), this synthetic (and partial) literature review shows that several studies have already focused on argumentative dynamics during parents-children verbal exchanges, emphasizing that conflict can be understood as a constructive and interactional process. Different argumentative strategies typically adopted both by parents to socialize their children to the values and norms typical of their own culture, and by children to oppose to their parents' argumentation have been documented. Within the field of developmental and social psychology, several studies have documented to what extent conflict has to be considered as a positive, normal and constructive dimension of life (e.g., Honess et al. 1997; Hartup et al. 1998; Arcidiacono 2007, 2008; Liberati and Arcidiacono 2007; Bova and Arcidiacono 2013a, 2014b). As highlighted by Shantz and Hartup (1992), conflict is an important aspect of personal and social development: «the central contention is that conflicts are microcosms of the linkages between adolescents' social relationships and their development as individuals» (p. 217). In other words, conflicts are not only related to social interaction, but they also contribute to the acquisition of conversational practices (Arcidiacono 2009) and improve different cognitive skills (Pontecorvo 1987). However, we believe that there is still a lack of knowledge of the types of issues leading parents and children to engage in argumentative/conflictual discussions, especially from the point of view of the recent argumentative theories that call researchers to identify the inferential work of interactants in their arguments' choices and uses. While the activity of mealtime has been deeply considered in the past by several scholars in order to investigate the verbal interactions among family members, so far, the pragmadialectical ideal model of critical discussions and the notion of argumentative discussion developed by van Eemeren and Grootendorst (2004) have not been used explicitly in research focused on family conflict. By carrying out this study, we want to extend the existing knowledge on family conflict by adopting this analytical approach, as well as the notion of argumentative discussion, which stems from the most recent developments of argumentation theory.

In particular, we aim to answer the following research questions: Which types of issues lead parents and children to engage in conflict in ordinary family conversations? To what extent the parents entering in argumentative discussions with their children aim to socialize them to family manners and values? How we can reach a comprehension of family members' inferential work in their conversational choice during argumentative discussions?

\section{Methodology}

\subsection{Data corpus}

The present investigation is part of a larger project devoted to the study of argumentation in the family context $^{2}$. The research design implies a corpus of 30 video-recorded mealtime conversations (constituting about twenty hours of video data), constructed from two different sets of data, named sub-corpus 1 and sub-corpus 2. All participants are Italian-speaking. The length of each recording varies from 20 to 40 $\min$.

Sub-corpus 1 consists of 15 video-recordings of mealtime conversations of five Italian families living in Rome. For the selection of the Italian families we recruited families including the presence of both parents and at least two children, with the younger of preschool age (three to six years) and the other of primary school age. Based on the parental answers to questionnaires about socio-economic status 
Pre-print copy of the article:

Bova, A., \& Arcidiacono, F. (2015). Beyond Conflicts: Origin and Types of Issues Leading to Argumentative Discussions during Family Mealtimes. Journal of Language Aggression and Conflict, 3(2).

(SES) and personal details that family members filled before the video-recordings, participants were middle to upper-middle-class families with high socio-demographic group.

Sub-corpus 2 consists of 15 video-recordings of mealtime conversations in five Swiss families living in the Lugano area. The criteria adopted in the selection of the Swiss families mirror the criteria adopted in the creation of sub-corpus 1.

\subsection{Transcription procedures}

All family meals were fully transcribed adopting the CHILDES standard transcription system CHAT (MacWhinney 2000), with some modifications introduced to enhance readability (see the Appendix for the conventions), and revised by two researchers until a high level of consent (agreement rate $=80 \%$ ) has been reached. Verbal utterances and nonverbal expressions with a clear communicative function relevant to the meal activity were identified and clearly described in the transcription.

In this paper, data are presented in the original (Italian), using regular font, whereas the English translation is added below using bold font. In all examples, all turns are numbered progressively within the discussion sequence, and family members are identified by role (for adults: father, mother) and by name (for children). In order to ensure the anonymity of children, the names in this paper are pseudonyms.

\section{Analytical approach}

The pragma-dialectical ideal model of a critical discussion is assumed, in the present study, as a grid for the analysis, since it provides the criteria for the selection of the conflictual argumentative discussions and for the identification of the types of issues, which lead to engaging in them.

\section{Selection of argumentative discussions and identification of the types of issues}

For the purposes of our study, the discussion is considered as argumentative if the following criteria are satisfied, according to the pragma-dialectical ideal model of a critical discussion:

(i) a difference of opinion between parents and children arises around a certain issue;

(ii) at least one standpoint advanced by one of the two parents is questioned by one or more children, or vice versa;

(iii) at least one family member (parent or child) puts forward at least one argument either in favour of or against the standpoint being questioned.

In order to identify the issues leading parents to engage in argumentative discussions with their children, the analysis will be focused on the first stage of the model of a critical discussion, i.e., the confrontation stage. In this stage the interlocutors establish that they hold different opinions about a certain issue: "the dialectical objective of the parties is to achieve clarity concerning the specific issues that are at stake in the difference of opinion" (van Eemeren and Grootendorst 1992,138). In this way, we take as ground for the analysis the conflictual sequences in which parents and children engage themselves in argumentative discussions.

\section{Results}


Pre-print copy of the article:

Bova, A., \& Arcidiacono, F. (2015). Beyond Conflicts: Origin and Types of Issues Leading to Argumentative Discussions during Family Mealtimes. Journal of Language Aggression and Conflict, 3(2).

Within the 30 video-recorded meals constituting the general corpus of this research, we found 127 argumentative discussions among family members. More specifically, the argumentative discussions between parents and children represent a large part of the corpus of argumentative discussions $(\mathrm{N}=107$; $84 \%)$.

What emerges by a preliminary synoptic analysis of the 107 selected sequences is that the argumentative discussions unfold around two different types of issues that can be described through one of the following two questions:

1) "Should child $X$ do Y?" This question allows one to consider all issues generated by an initial prescription by one of the two parents to which (at least) one of the children showed to be in disagreement;

2) "May child $X$ do $Y$ ?" This question allows consideration of all issues generated by an initial request by one of the children to which (at least) one of the two parents showed to be in disagreement.

In most cases, the issues leading parents and children to engage in argumentative discussions were generated by parental prescriptions $(\mathrm{N}=76 ; 71 \%)$, and were related to the following categories (cf. Figure 1): feeding practices ${ }^{3}$; teaching of correct table manners; and social behavior of children outside the family context.

\section{INSERT HERE FIG. 1}

Almost one-third $(\mathrm{N}=31 ; 29 \%)$ of the issues leading parents and children to engage in argumentative discussions were instead generated by children's requests. In particular, we observed that these issues relate to the following categories (cf. Figure 2): eating behaviors; teaching of correct table manners; and behavior of children and parents both outside and within the family context. The categories are somewhat similar to the issues used by parents in their prescriptions to children. However, in children's requests we found, although with minimal frequency, that the behavior at home (concerning both parents and children) is evoked as an issue leading argumentative discussions, as well as the social behavior of the adults outside the family context.

\section{INSERT HERE FIG. 2}

The findings of this study indicate that the argumentative discussions unfold around issues that are generated most frequently by parental prescriptions and less frequently by children's requests. In particular, according to the ideal model of a critical discussion, the parents often play the crucial argumentative role of protagonist, while the children play a role of active antagonist, because they impose the burden of proof on their parents by putting their prescriptions into doubt. The notion of burden of proof implies that when a party advances a standpoint, she/he commits her/himself to defend her/his position by putting forward (at least) one argument in its support. When she/he does, she/he assumes the burden of proof; when she/he does not, she/he does not accept to assume the burden of proof (van Eemeren 2010; van Eemeren and Houtlosser 2002).

Our findings are also connected to the results of other studies that have analyzed family mealtime conversations. For example, Kendall (2008) has shown that the discursive positions fathers and mothers take up are oriented to negotiating authority and favoring connection with children. In particular, when mothers perform more meal-related and sociable functions, fathers support them discursively. This capacity to assume different positions within several interactional situations contributes to define the frames in which family members engage in argumentative discourses. Further evidence of these aspects is offered by Arcidiacono and Pontecorvo (2010) about parents' discursive positions, and by Aronsson and Gottzén (2011) concerning the ways in which people shift between distinct intergenerational positions during family interactions at dinnertime. 
Pre-print copy of the article:

Bova, A., \& Arcidiacono, F. (2015). Beyond Conflicts: Origin and Types of Issues Leading to Argumentative Discussions

during Family Mealtimes. Journal of Language Aggression and Conflict, 3(2).

In discussing the results, we present a selection of some excerpts representative (in terms of modality and frequency) of the results obtained from the entire corpus of argumentative discussions between parents and children. An analysis of conflictual conversations will offer a view of the types of issues leading family members to argumentative discussions at mealtimes.

\section{Issues generated by parental prescriptions}

Even though the issues generated by parental prescriptions also include the social behavior of children outside the family context, they are in large part strictly bounded to the specific situational activity children are involved in, i.e., the activity of mealtimes. In fact, these issues frequently concern the feeding practices. The following discussion between a father and his 7-year-old son, Samuele, offers an illustration of how a parental prescription related to feeding practices can trigger the beginning of an argumentative discussion.

\section{Excerpt 1}

Italian family. Participants: father (DAD, 38 years), mother (MOM, 34 years), Samuele (SAM, 7 years 2 months), Daniele (GAB, 5 years 4 months).

\%sit: SAM sta bevendo una bibita gassata

SAM is drinking a soft drink

1. *DAD: basta bere XXX ((nome della bibita gassata)) Samuele!

stop drinking XXX ((name of the brand of the soft drink)) Samuele!

$\rightarrow \quad$ *DAD: adesso ti do il riso. now I'll give you some rice.

2. *SAM: no, non voglio altro: ((sedendosi sulla sedia))

no, I don't want anything else: ((sitting on the chair))

$\rightarrow \quad$ *SAM: per favore, niente. [:!facendo cenni di negazione col capo]

please, no more. [:! shaking his head in refusal]

3. *DAD: no:: non hai mangiato abbastanza.

no:: you haven't eaten enough.

4. *SAM: no:::

no:::

*SAM: no:: sono pieno:

no:: I'm full:

\%act: SAM guarda verso DAD e inizia a bere nuovamente la bibita gassata

SAM looks towards DAD and starts drinking the soft drink again

5. *DAD: ti ho detto:: Samuele basta bere questa roba ((la bibita gassata)

I told you:: Samuele stop drinking this stuff ((the soft drink))

\%act: DAD prende il bicchiere di SAM e lo porta in cucina

DAD takes SAM's glass and takes it to the kitchen

The excerpt is opened by a father's directive (line 1) that can be interpreted as implicitly condensing a standpoint and a justification: in the analytical reconstruction of argumentation, the father's claim concerns an invitation to the child ("you should eat some food"), followed by a justification ("because you are drinking too much"). It is in line 2 that a difference of opinion between Samuele and his father arises. The child's intervention constitutes the beginning of the argumentative discussion, as the child replies to the father that he does not want to eat anything else. What is interesting in argumentative terms is the fact that the father's directive (to stop drinking and to start eating) is contrasted by Samuele's reaction, which is essentially towards the second part of the father's prescription. In fact, in his discursive strategic manoeuvre, Samuele does not consider the fact that he has to stop drinking, but immediately focuses on the main claim of the parent, namely to convince the child to eat the rice. This choice in the answer of Samuele (a refusal of the father's proposal through a counter-position on his argument) 
determines the orientation of the discussion exclusively around the food. The father ratifies this specific direction of the argumentative discussion in line 3, as he puts forward an argument based on the quantity of food. However, as we can observe from Samuele's answer in line 4, this argument is not effective enough to convince the child to accept the father's standpoint. The opposition of Samuele ("no::: no:: I'm full") determines a change of strategy in the father's position. The adult turns back to the first prescription (to stop drinking) in order to make explicit the fact that Samuele cannot discuss the parental issue anymore. In fact, the father's prescription is advanced again through the use of the expression "I told you:: Samuele" (line 5) and through the action of taking the soft drink away from Samuele. From the father's perspective, this last intervention is a way to re-conduct the discussion to the first level, giving as an argument the inappropriate conduct of Samuele who is drinking instead of eating. From the point of view of the analytical reconstruction of the argumentation, the adult's interventions could be interpreted as specific forms of strategic manoeuvring, motivated by the respect of certain family customs (such as, "if you don't eat, you can't drink"). Gaining further insights on the context of family conversations can provide a richer perspective on the goals dominating the participants' strategic manoeuvring: what could be interpreted as an imposition of order could turn out to be a constructive move aiming at teaching the value of argumentation as a rational way to solve differences of opinion.

The contingency of the activity during mealtimes is an issue that participants often invoke during their exchanges in order to prescribe a behavior linked to the situation. In our data, we frequently found that parents and children engaged in argumentative discussion on account of parental prescriptions related to having to eat a certain food. These results are in line with previous studies on family discourse at mealtimes. For example, within the discursive psychology perspective, Wiggins and colleagues (2002, 2004; Wiggins and Potter 2003) have documented to what extent conversations between parents and young children during mealtimes are typically food-oriented.

However, parental prescriptions did not pertain exclusively to feeding practices, but also to the teaching of correct table manners. We can refer to the following example in order to observe how other, different types of parental prescriptions can generate issues that lead parents to engage in argumentative discussions with their children.

\section{Excerpt 2}

Italian family. Participants: father (DAD, 37 years), mother (MOM, 37 years), Gabriele (GAB, 8 years 5 months), Adriana (ADR, 4 years 4 months).

\%act: $\quad$ GAB si alza da tavola e sta per andare a sedersi sul divano

\begin{tabular}{|c|c|c|}
\hline \multirow{3}{*}{1.} & \multirow{3}{*}{ *MOM: } & GAB gets down from the table and he is about to go and sit on the couch \\
\hline & & Gabriele, non puoi andare a guardare la TV sul divano \\
\hline & & Gabriele, you can't go to watch TV on the couch \\
\hline & \multirow[t]{2}{*}{ \%act: } & GAB torna a sedersi a tavola \\
\hline \multirow{3}{*}{2.} & & GAB comes back to sit at the table \\
\hline & \multirow[t]{2}{*}{ *GAB: } & ma io voglio guardare la TV sul divano! \\
\hline & & but I want to watch TV on the couch! \\
\hline \multirow[t]{2}{*}{3.} & \multirow[t]{2}{*}{ *MOM: } & Gabriele, quando si mangia non ci si alza da tavola \\
\hline & & Gabriele, during mealtimes you cannot get down from the table \\
\hline 4. & *GAB: & $\begin{array}{l}\text { perché no? } \\
\text { why not? }\end{array}$ \\
\hline \multirow[t]{2}{*}{5.} & \multirow[t]{2}{*}{ *MOM: } & perché è maleducato farlo \\
\hline & & because it is ill-mannered to do it \\
\hline \multirow[t]{3}{*}{6.} & *GAB: & $\mathrm{mmm}$ \\
\hline & \multirow{2}{*}{ \%act: } & GAB continua a mangiare rimanendo seduto a tavola \\
\hline & & GAB remains seated at the table and continues to eat \\
\hline
\end{tabular}


Pre-print copy of the article:

Bova, A., \& Arcidiacono, F. (2015). Beyond Conflicts: Origin and Types of Issues Leading to Argumentative Discussions during Family Mealtimes. Journal of Language Aggression and Conflict, 3(2).

In this sequence, the difference of opinion is between the mother and her 8-year-old son, Gabriele. The child gets down from the table and he is about to go and sit on the couch to watch TV. The mother disagrees with her son's behavior, and makes her standpoint explicit in line 1. However, the adult's prescription, in its actual form, does not account for any reasons. The fact that he is not allowed to go watch TV is interpreted by Gabriele as a prescription in contrast with his desire. In fact, in line 2 the child, who came back to sit at the meal-table, disagrees with his mother and advances his standpoint using the adversative form "but" in order to mark the different position with respect to the adult statement. This sequence (lines 1 and 2) represents a confrontation stage, as the mother's standpoint meets with the child's opposition. In this phase of the discussion, the issue leading the mother to engage in an argumentative discussion with her son is related to the teaching of correct table manners. But in order to understand the issue discussed in the presented sequence, the circumstances in which the argumentation takes place must be taken into account. In the present case, the possibility of watching TV is not a topic of discussion per se, but it is the fact that family rules, at least for this family, imply finishing dinner before going to do other activities (including watching TV on the couch). The discursive interventions of Gabriele have played a crucial role in this sense, because the child has challenged the interlocutor to defend her standpoint. Based on this issue, the mother has been obliged to specify the reasons of her prescription, and to justify why it was not allowed to leave the table within the observed situation. From a linguistic point of view, the implicit accusation made by Gabriele (the impossibility of going to watch TV despite his wish, "I want...") requires the parent to give a justification. The question is whether and how the participants use the potential of dissent to handle the critical question argumentatively. Finally, after the unilateral obligation, the mother offers a strong dissent preventing the possibility of continuing the debate.

In family conversations, participants are frequently accusing, blaming, complaining, criticizing, reprimanding, rebuking, expressing dissatisfaction with or criticism of a preceding or current activity, attitude or characteristic on the part of the defendant. As a consequence, when social rules are violated or fail to meet expectations, sequences of conflict can appear in order to solve situational accusations (Gruber 2001). Less frequently, in our corpus, the issues leading parents to engage in argumentative discussions with their children were generated by parental prescriptions that pertain to the behavior of children in social interactions outside the family. These types of issues largely refer to the school and, in particular, to children's behavior with teachers and schoolmates. The following example is an illustration of how an issue generated by a parental prescription and related to a child's behavior in the school context leads a father to engage in an argumentative discussion with his 8-year-old son, Silverio.

\section{Excerpt 3}

Italian family. Participants: father (DAD, 38 years), mother (MOM, 38 years), Silverio (SIL, 8 years), Gabriele (GAB, 5 years 4 months).

1. $\quad$ *SIL: $\quad$ oggi, la maestra non mi ha fatto andare al bagno

2. today, the teacher didn't let me go to the bathroom

2. $\quad$ DAD: devi ascoltare le regole della maestra!

3. $\quad$ SIL: $\quad \begin{aligned} & \text { you must listen to the teacher's rules! } \\ & \text { perché diceva, che possiamo andare solo alla fine della lezione }\end{aligned}$

because she said, that we can only go at the end of the lesson

$\rightarrow \quad$ *SIL: $\quad$ quando: suona la campanella

when: the bell rings

$4 \quad$ *DAD: $\quad$ e tu cosa hai fatto?

5. $\quad$ *SIL: $\quad$ and what did you do?

I told her that it wasn't right

6. $\quad$ DAD: $\quad$ non devi rispondere male alla maestra, devi ascoltare quello che ti dice!

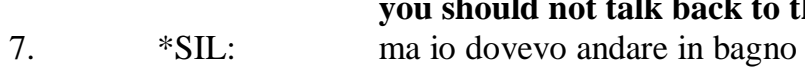


Pre-print copy of the article:

Bova, A., \& Arcidiacono, F. (2015). Beyond Conflicts: Origin and Types of Issues Leading to Argumentative Discussions during Family Mealtimes. Journal of Language Aggression and Conflict, 3(2).

\begin{tabular}{|c|c|c|}
\hline \multirow[b]{2}{*}{8} & & but I had to go to the bathroom \\
\hline & *DAD: & è maleducato rispondere alla maestra, lo sai? \\
\hline & & it's bad manners to talk back to the teacher, you know? \\
\hline 9. & *SIL: & si, lo so. \\
\hline 10. & *DAD: & $\begin{array}{l}\text { e allora non lo fare più! } \\
\text { so do not do it anymore! }\end{array}$ \\
\hline 11. & *SIL: & $\begin{array}{l}\text { mmm:: ((con un'espressione triste })) \\
\text { mmm:: ((with a cheerless expression on his face }))\end{array}$ \\
\hline
\end{tabular}

The sequence begins with the child, Silverio, who is informing his father that at school that day, the teacher had not permitted him to go to the bathroom. In line 2, the father immediately makes his standpoint explicit, telling Silverio that he must follow the teacher's rules, thus opposing the child's standpoint. The father is not asking Silverio to account for the teacher's prohibition. He is immediately appealing to the authoritative role of the teacher in order to reply to the child. The father's position is orienting the exchange towards the endoxon that the teacher's rules have to be respected. Within this sequence, Silverio provides the reasoning that the teacher used to justify the prohibition (turn 3 ). In turn, the father shows himself to be more interested in knowing the behavior of his son ("and what did you do?") than in judging the reasoning underlying the teacher's prohibition. This intervention opens the ground for the child to add some elements in support of his initial complaint about the prohibition of the teacher. It is a way to enlarge Silverio's response duties, calling him to argue on an equal footing with his father. In fact, Silverio is able to express his point of view with respect to the teacher's veto. In line 5, the child tells his father that he told the teacher that the prohibition was, according to him, not right. However, the father shows to be more interested in the argument of authority (of the teacher) than in the opinion of the child about the prohibition. In fact, the father disapproves of the son's behavior (line 6, "you shouldn't talk back to the teacher, you must listen to what she says"), appealing to a general rule at school, namely the fact that it is not possible to disagree with the teacher's directives. In this way, the fathers is recalling the endoxon announced at the beginning of the sequence, asking the child to align to his argument of authority of the teacher. The father's intervention can be viewed as an opposition turn involving a comment upon what was said in the prior turn, but the appeal to the general assumption and principle connected to the institutional value of the teacher's role can be also intended as a way to avoid further discussions. In fact, following the father's orientation, there is no way to debate the teacher's rules at school. However, the intervention of Silverio puts the father in the position to add some further arguments sustaining his standpoint. By his intervention in turn 7, "but I had to go to the bathroom," the child starts out to repair a potential misunderstanding (his physiological need instead of the choice of answering back the teacher). In this sense, the sequence is particularly interesting because there is a confrontation stage where the father's standpoint, "you must listen to the teacher's rules," meets with the child's opposite view, "I told to the teacher that it wasn't right." By focusing on this phase of the discussion, we can highlight that the issue leading the father to engage in an argumentative discussion with his son is related to the behavior of the child in the school context, and not to the appropriateness of the teacher's prohibition. While Silverio tries to justify his reaction on the assumption that the teacher's prohibition was not right, the father uses the argument of authority (based on a commonplace statement, "it's bad manners to talk back to the teacher, you know?") in order to underline that at school it is not possible to disagree with the teacher's directives. In this sense, speakers can deny the opponent's status/behavior by challenging the position put forward in the confrontation stage. In line 10 , the father ends the sequence ("so do not do it anymore!") by recommending Silverio not to repeat the same mistake in the future. From a linguistic point of view, the final father's statement suspends the topic as a subject of discussion: the pragmatic device "so" presents his position as a generally acceptable regulation that is not open to further discussion. The child accepts this intervention of the father, although with a cheerless expression on his face. According to Goodwin (2006), it seems that in their orientation to future actions, 
Pre-print copy of the article:

Bova, A., \& Arcidiacono, F. (2015). Beyond Conflicts: Origin and Types of Issues Leading to Argumentative Discussions

during Family Mealtimes. Journal of Language Aggression and Conflict, 3(2).

both parties are willing to negotiate in a macro-perspective, namely, the future behavior of Silverio at school.

\section{Issues generated by children's requests}

More frequently, the issues generated by children's requests concern activities closely related to mealtimes, such as eating behaviors and teaching of correct table manners by parents. These results are in line with the frequencies we found in the analysis of parental prescriptions. For instance, it is interesting to highlight that the use of the issue leading to engage in argumentative discussions is different in the children's view. The following dialogue between a father and his 7-year-old daughter, Manuela, is an example of how a child's request to the adult related to having to eat a certain food can trigger the beginning of an argumentative discussion.

\section{Excerpt 4}

Swiss family. Participants: father (DAD, 39 years), mother (MOM, 34 years), Manuela (MAN, 7 years 4 months), Filippo (FIL, 5 years 1 month), Carlo (CAR, 3 years 1 month).

1. MAN: $\quad$ questo poco di pasta lo posso lasciare? ((sollevando leggermente il suo piatto per mostrarne il contenuto al papà))

can I leave this little bit of pasta? ((slightly raising the plate to show the contents to her father))

2. DAD: no, non puoi

3. MAN: $\quad \begin{aligned} & \text { no, you can't } \\ & \text { perché, papà? }\end{aligned}$

$\begin{array}{ll} & \text { why, dad? } \\ \text { 4. } & \text { DAD: }\end{array}$ you haven't eaten anything, Manuela.

In this exchange, the difference of opinion between the child, Manuela, and her father concerns the amount of pasta to be eaten: Manuela wants to leave a little bit of pasta that is still on her plate, but the father disagrees with her (line 2, "no, you can't"). While the child's expression, "this little bit," aims to obtain a concession, the father, on the contrary, replies with a prohibition. The adult's intervention opens the ground for an argumentative discussion because two opposite standpoints are expressed by the participants. By asking a why-question (line 3), Manuela is interested in challenging the parental prohibition, and she shows her willingness to know the reasons on which the father's prohibition is based. This position is argumentatively strategic because it obliges the father to put forward an argument in support of his standpoint (line 4, “you haven't eaten anything, Manuela"), rebutting the daughter's argument based on this little bit. But the argument related to the presumed quantity of food that has to be eaten closes the child's possibility to extend the argumentative exchange. In fact, the reason for the prescription is connected to the non-consistent behavior of Manuela during the dinner and, for this reason, there is no further space for debating about why the child cannot leave some food.

We have observed that the issues leading parents to engage in argumentative discussions with their children were also generated by children's requests pertaining to the possibility of teaching the children how to behave properly, both in social interactions outside the family context, especially at school, and within the family context. From a different perspective - developmental and not, as in our case, argumentative - similar results were also found by Dunn and Munn (1987). For instance, the following example provides an illustration of how a request by the 4-year-old son, Alessandro, who wants to take a pill from the drug's container, can lead to an argumentative discussion with his mother.

\section{Excerpt 5}


Swiss family. Participants: father (DAD, 36 years), mother (MOM, 34 years), Stefano (STE, 8 years 5 months), Alessandro (ALE, 4 years 6 months).

$\%$ sit: $\quad$ ALE tocca e guarda il contenitore delle medicine

ALE touches and looks at the container with the pills

1. $\quad$ *ALE: $\quad$ io: me la prendo una di queste qui.

I'm: going to take one of these.

$\rightarrow \quad$ *ALE: $\quad$ si!

2. $\quad$ *MAM: $\quad$ nes! $\quad$ non puoi, Alessandro!

3. $\quad$ you can't, Alessandro!

3. *ALE: che?

4. $\quad$ *MOM: $\quad$ non puoi. ((scuotendo la testa))

5. $*$ you can't. ((shakes her head))

5. *ALE: perché no?

6. $*$ MOM: $\quad$ perché i bambini, devono prendere delle medicine speciali

because children, have to take special drugs

$\rightarrow \quad$ *MOM: $\quad$ non possono prendere le medicine degli adulti

they can't take drugs for adults

$\rightarrow \quad *$ MOM: $\quad$ altrimenti, si sentono male.

7. $\quad$ ALE: $\quad$ otherwise, they will get sick.

and before did you also feel sick?

8. $\quad$ MOM: no, perché io sono un'adulta

9. no, because I'm an adult

9. *ALE: $\quad$ e io?

10. $\quad$ MOM: $\quad$ tu sei ancora: un bambino

you are still: a child

\%pau: $\quad 1.0 \mathrm{sec}$

\%sit: $\quad$ ALE sbatte la scatola delle medicine sul tavolo MAM tende la mano verso di lui per fargli mangiare un pezzetto di frutta ALE volta la testa di scatto e lentamente esce dalla cucina dirigendosi verso DAD e STE

Alessandro bangs the medicine container on the table. MOM reaches toward him to try to make him eat a piece of fruit. ALE turns his head away quickly and slowly leaves the kitchen to go toward DAD and STE

In this exchange, the issue leading the mother to engage in an argumentative discussion with Alessandro is related to teaching the child a proper behavior at home. The sequence begins when the child tells the mother of his intention to take a pill from the container. The pre-sequence used by Alessandro (line 1, "I'm going to...") announces his action and reinforces his position by concluding his remark with "yes." The argumentative discussion is opened by the mother, in lines 2 and 4, when she disagrees with the child's behavior, twice repeating, "You can't." This phase of the discussion is the confrontation stage, as there is a standpoint (I want to take a pill from the container) that meets with the mother's refusal (You can't, Alessandro). As in previous cases, the argumentative strategy used by the child is the why-question to the adult in order to challenge the mother to defend her standpoint. In doing so, Alessandro makes no effort to defend his position by putting forward arguments on his own behalf; instead, he requests the burden of proof by assuming a waiting position before accepting or putting into doubt the parental prescription. The mother does not avoid justifying her prohibition, putting forward her argument and evoking a general rule - children have to... - to which Alessandro is also subject.

Interestingly, in the corpus we also observed one case where the issue leading to an argumentative discussion was related to the behavior of parents outside the family context, and one case to the parental conduct within the family context. These two issues, both generated by children's requests, can be 
Pre-print copy of the article:

Bova, A., \& Arcidiacono, F. (2015). Beyond Conflicts: Origin and Types of Issues Leading to Argumentative Discussions during Family Mealtimes. Journal of Language Aggression and Conflict, 3(2).

described as follows: May Mom go to the sports hall to pick up Paolo? May Mom prepare breakfast for Dad every day? Due to the lack of space we are not presenting excerpts related to the two cases.

\section{Discussion}

In line with what was already observed by Blum-Kulka (1997) in her cross-cultural study on family dinner conversations, the results of this study indicate that argumentative discussions are not primarily aimed at resolving verbal conflicts among family members, but they essentially appear to be an instrument that enables parents to transmit, and children to learn values and models about how to behave in a culturally appropriate way. Mealtimes appear as activity settings and opportunity spaces where family members intentionally and unintentionally express their feelings and expectations. Of course, just because opportunities exist does not mean they are taken. In our case, we observed that the argumentative discussions unfold around issues that are generated both by parental prescriptions and by children's requests. The parental prescriptions largely concern context-bound activities such as having to eat a certain food or teaching correct table manners. The issues triggered by children's requests refer to a wide range of activities, mainly context-bound, but also in some cases context-unbound, such as the children's behavior outside and within the family context.

The observed dynamics characterizing family discussions reveal that argumentation is a coconstructed activity in which children play a role that is equally fundamental to that of their parents. Through the use of an argumentative model of analysis, we have observed to what extent argumentative interactions should be viewed as a bidirectional process of mutual apprenticeship where parents affect children and are simultaneously affected by them. By their reciprocal engagement in conflictual discussions, parents and children jointly produce and transform the social order and their positions within the family frameworks, through the formatting and sequencing of actions and their responses. These participants' dynamics are evident in the manifest collision of control manoeuvres and resistance in argumentative sequences. By engaging in argumentative discussions, parents accept (assume) the commitment to transmit rules, values, and correct behaviors to their children. By participating in argumentative discussions with their parents, children can become more aware of their active role within the family context. The analytical reconstruction of how family members dialectically solve differences of opinion is thus a useful way to highlight choices, forms, and dynamics adopted by adults and children at mealtimes.

The argumentative exchanges we have observed in our data appear as areas of socialization in which accusations are used as declarative statements where a family member explicitly mentions the activity or the attitude that constitutes a violation, attributing a negative quality to it. For example, parents engage in argumentative discussions with their children to teach them how to behave appropriately not only at the meal-table, but also in all situations in which children can be in contact with other people outside the family context. The school context and the children's behavior with their peers, e.g., schoolmates, represent in particular the issues parents are most concerned about. A possible implication of this aspect concerns how the children's capacity to engage in argumentative discussions with their parents could influence their future capacity to be actively involved in exchanges with other adults.

In our view, within the family context, conflicts can contribute to improving conversational, social, and cognitive skills of adults and children. Conflicts can be seen as constitutive, not just disruptive, of social life (Garcés-Conejos Blitvich 2010), leading adults and children to constantly renegotiate the norms of interaction, and contributing to construct the family borders from a social and linguistic point of view. For this reason, a focus on the moves of people during daily argumentative/conflictual discussions is, in our opinion, a way to understand how parents and children recognize continuously what they are doing and what they have to do with the interlocutors. As people 
Pre-print copy of the article:

Bova, A., \& Arcidiacono, F. (2015). Beyond Conflicts: Origin and Types of Issues Leading to Argumentative Discussions during Family Mealtimes. Journal of Language Aggression and Conflict, 3(2).

can deal with disagreements by means of reasonable argumentative exchanges (Arcidiacono 2011), this capacity is considered as a resource within the family context.

From an argumentative perspective, we believe that the role of children is not less important than the role of their parents. Through the analysis of argumentative sequences, we have seen that their presence and involvement in family conversations favors the beginning of argumentative discussions and represents a stimulus factor, inducing parents to reason with their children. Through their continuous questioning, children show their desire to find out the - often implicit - reasons on which their parents' standpoints are based ${ }^{4}$. These questions reflect the children's desire to know and find out what is, until that point, unknown to them (Bova and Arcidiacono 2013b). The questions asked by children to their parents and to caregivers in general, represent a great educational opportunity; because of the children's questions, the parents need to advance arguments in support of their own standpoint. It is a responsibility of parents and caregivers in general to take advantage of the opportunity offered by children's questions, providing the educational responses that children need. For the reasons mentioned above, therefore, we believe that while the parents play the role of "educators" during argumentative discussions, the children play the not less important role of "active learners." This aspect is connected to the value of family conversations as spaces in which dynamics of generational positions can be developed as part of language socialization and interactional events (Aronsson and Gottzén 2011).

We would like to conclude with some remarks and further directions on lessons learned from our research. On the one hand, the present study had at least one limitation; because the investigation relies on participants' interventions within a specific family activity, the generalization of the results is tenuous. The possibility of exploring how different argumentative stages influence participants' discussions in other types of interaction will offer a way to test the effect of argumentative exchanges outside the family (Arcidiacono 2013, 2014). On the other hand, more generally, the findings we found in our study can have relevant implications at different levels; as parents and children engage in argumentative exchanges during everyday conversations, specific attention to precise linguistic elements can be a way to further consider the issues we have highlighted by our argumentative analysis. For example, as suggested by $\mathrm{M}$. H. Goodwin (2007), it will be interesting to explore how explanations in family conversations are recipient-designed and contribute to children's involvement in the discussion as a collaborative production of utterances. A specific analysis of this (and other) linguistic aspect(s) will allow us to better understand the interplays of action, cognition, and effect within situated activities (Goodwin C. 2007) as a joint arrangement that is crucial for apprenticeship in the family context.

\section{Acknowledgments}

This work was supported by the Swiss National Science Foundation (SNSF) [grant number PDFMP1123093/1] as part of the Research Module "Argumentation as a reasonable alternative to conflict in the family context".

\footnotetext{
Notes

1 In their model to reconstruct and analyse the inferential configuration of the arguments advanced by discussants in argumentative exchanges, the Argumentum Model of Topics (AMT), Rigotti and Greco Morasso (2010) propose to reconsider the Aristotelian notion of endoxon. According to the authors, endoxa are context-bound principles, values, and assumptions that are typically "accepted by the relevant public or by the opinion leaders of the relevant public", and which often represent shared premises in argumentative discussions (ibid., p. 501).

2 We are referring to the Research Module "Argumentation as a reasonable alternative to conflict in the family context" (project n. PDFMP1-123093/1) funded by the Swiss National Science Foundation (SNSF). In turn, this Research Module is part of one of several research projects devoted to the study of the socializing function of argumentative interactions between adults and young children (aged from 3 to 9 years) developed within the *ProDoc Argupolis (www.argupolis.net) and involving scholars coming from the Università della Svizzera italiana (USI), the University of Neuchâtel (UNINE), the University of Lausanne (UNIL), and the University of Amsterdam (UVA).

${ }^{3}$ With the term feeding practices we refer to the parents' activity of trying to teach their children adequate eating behaviours.
} 
Pre-print copy of the article:

Bova, A., \& Arcidiacono, F. (2015). Beyond Conflicts: Origin and Types of Issues Leading to Argumentative Discussions during Family Mealtimes. Journal of Language Aggression and Conflict, 3(2).

${ }^{4}$ As observed by Ervin-Tripp and Strage (1985), parental prescriptions that are implicit or based on rules not initially known by children base their strength and effectiveness mainly on parents' authority.

\section{References}

Arcidiacono, Francesco. 2007. Conflitti e Interazione in Famiglia. Rome: Carocci.

Arcidiacono, Francesco. 2008. "Les Interactions Asymétriques en Famille: Analyse Qualitative du Conflit Verbal dans les Conversations à Table." Cahiers de Psychologie 43:33-41.

Arcidiacono, Francesco. 2009. "Conflitti Verbali in Famiglie con Preadolescenti: Modelli di Analisi in Chiave Conversazionale." Giornale Italiano di Psicologia 36(4):821-841.

Arcidiacono, Francesco. 2011. "But who said that you eat when you want and what you want?' Verbal Conflicts at Dinnertime and Strategic Moves among Family Members." In Family Conflicts: Psychological, Social and Medical Implications, edited by James P. Flanagan and Alexander M. Munos, 27-52. New York NY: Nova Science Publishers.

Arcidiacono, Francesco. 2013. "Conversation in Educational Contexts: School at Home and Home at School." In Crossing Boundaries. Intercontextual Dynamics between Family and School, edited by Giuseppina Marsico, Koji Komatsu and Antonio Iannaccone, 83-107. Charlotte NC: Information Age Publishing.

Arcidiacono, Francesco. 2014. "Argumentation and Reflexivity." In The Yearbook of Idiographic Science. Volume 6: Reflexivity and Change in Psychology, edited by Giuseppina Marsico, Ruggero Ruggieri and Sergio Salvatore. Charlotte NC: Information Age Publishing.

Arcidiacono, Francesco, and Antonio Bova. 2011. "Argumentative Strategies for Conflict Management and Resolution in Italian and Swiss Families." Procedia Social and Behavioral Sciences 30:13851389.

Arcidiacono, Francesco, and Clotilde Pontecorvo. 2009. "Cultural Practices in Italian Family Conversations: Verbal Conflict between Parents and Preadolescents." European Journal of Psychology of Education 24(1):97-117.

Arcidiacono, Francesco, and Clotilde Pontecorvo. 2010. "The Discursive Construction of the Fathers' Positioning within Family Participation Frameworks." European Journal of Psychology of Education 25(4):449-472.

Arcidiacono, Francesco, Clotilde Pontecorvo, and Sara Greco Morasso. 2009. "Family Conversations: The Relevance of Context in Evaluating Argumentation." Studies in Communication Sciences 9(2):79-92.

Aronsson, Karin, and Lucas Gottzén. 2011. "Generational Positions at a Family Dinner: Food Morality and Social Order." Language in Society 40(4):405-426.

Blum-Kulka, Shoshana. 1993. "YYou gotta know how to tell a story': Telling, Tales, and Tellers in American and Israeli Narrative Events at Dinner. Language 22(3):361-402.

Blum-Kulka, Shoshana. 1994. “The Dynamics of Family Dinner Talk: Cultural Contexts for Children's Passages to Adult Discourse. Research on Language and Social Interaction 27(1):1-50.

Blum-Kulka, Shoshana. 1997. Dinner Talk: Cultural Patterns of Sociability and Socialization in Family Discourse. Mahwah NJ: Erlbaum.

Blum-Kulka, Shoshana. 2008. "Language socialization and family dinnertime discourse." In Encyclopedia of Language and Education. Vol. 8: Language Socialization, edited by Patricia A. Duff and Nancy H. Hornberger, 87-99. New York NY: Springer Science.

Bousfield, Derek. 2013. "Face in Conflict.” Journal of Language Aggression and Conflict 1(1):37-57.

Bova, A. forthcoming. "Adult as a Source of Expert Opinion in Child's Argumentation during Family Mealtime Conversations.” Journal of Argumentation in Context. 
Pre-print copy of the article:

Bova, A., \& Arcidiacono, F. (2015). Beyond Conflicts: Origin and Types of Issues Leading to Argumentative Discussions during Family Mealtimes. Journal of Language Aggression and Conflict, 3(2).

Bova, Antonio, and Francesco Arcidiacono. 2013a. "Invoking the Authority of Feelings as a Strategic Maneuver in Family Mealtime Conversations." Journal of Community and Applied Social Psychology 23(3):206-224.

Bova, Antonio, and Francesco Arcidiacono. 2013b. "Investigating Children's Why-Questions. A Study Comparing Argumentative and Explanatory Function.” Discourse Studies 15(6):713-734.

Bova, Antonio, and Francesco Arcidiacono. 2014a. "'You must eat the salad because it is nutritious'. Argumentative Strategies Adopted by Parents and Children in Food-Related Discussions at Mealtimes." Appetite 73(1):81-94.

Bova, Antonio, and Francesco Arcidiacono. 2014b. "Types of Arguments in Parents-Children Discussions: An Argumentative Analysis." Rivista di Psicolinguistica Applicata/Journal of Applied Psycholinguistics 14(1):43-66.

Brumark, Åsa. 2008. “'Eat your Hamburger!' - 'No, I don’t Want to!' Argumentation and Argumentative Development in the Context of Dinner Conversation in Twenty Swedish Families." Argumentation 22(2):251-271.

Dunn, Judy, and Penny Munn. 1987. "Developmental of Justification in Disputes with Mother and Sibling." Developmental Psychology 23(6):791-798.

van Eemeren, Frans H. 2010. Strategic Maneuvering in Argumentative Discourse. Amsterdam: Benjamins.

van Eemeren, Frans H., and Peter Houtlosser. 2002. "Strategic Maneuvering with the Burden of Proof." In Advances in Pragma-Dialectics, edited by Frans H. van Eemeren, 13-28. Amsterdam/Newport News VA: Sic Sat/Vale Press.

van Eemeren, Frans H., and Rob Grootendorst. 1992. Argumentation, Communication, and Fallacies. A Pragma-Dialectical Perspective. Hillsdale NJ: Erlbaum.

van Eemeren, Frans H., and Rob Grootendorst. 2004. A Systematic Theory of Argumentation: The Pragma-Dialectical Approach. Cambridge: Cambridge University Press.

Ervin-Tripp, Susan M., \& Amy A. Strage. 1985. "Parent-Child Discourse." In Handbook of Discourse Analysis. Vol. 3: Discourse and Dialogue, edited by Teun A. van Dijk, 67-77. New York NY: Academic Press.

Farris, Catherine. 2000. "Cross-Sex Peer Conflict and the Discursive Production of Gender in a Chinese Preschool in Taiwan.” Journal of Pragmatics 32(5):539-568.

Fiese, Barbara H., Kimberly P. Foley, and Mary Spagnola. 2006. "Routine and Ritual Elements in Family Mealtimes: Contexts for Child Well-Being and Family Identity." New Directions for Child and Adolescent Development 111:67-89.

Garcés-Conejos Blitvich, Pilar. 2010. "A Genre Approach to the Study of Im/politeness." International Review of Pragmatics 2(1):46-94.

Goodwin, Charles. 2006. "Retrospective and Prospective Orientation in the Construction of Argumentative Moves." Text \& Talk 26(4-5):443-461.

Goodwin, Charles. 2007. "Participation, Stance and Affect in the Organization of Activities." Discourse \& Society 18(1):53-73.

Goodwin, Marjorie H. 2007. "Occasioned Knowledge Exploration in Family Interaction.” Discourse \& Society 18(1):93-110.

Gordon, Cynthia. 2008. "A(p)parent Play: Blending Frames and Reframing in Family Talk." Language in Society 37(3):319-349.

Greco Morasso, Sara. 2008. “The Ontology of Conflict.” Pragmatics \& Cognition 16(3):540-567. Gruber, Helmut. 2001. "Questions and Strategic Orientation in Verbal Conflict Sequences.” Journal of Pragmatics 33(12):1815-1857. 
Pre-print copy of the article:

Bova, A., \& Arcidiacono, F. (2015). Beyond Conflicts: Origin and Types of Issues Leading to Argumentative Discussions during Family Mealtimes. Journal of Language Aggression and Conflict, 3(2).

Hamilton, Mark A., and Melissa A. Tafoya. 2012. "Relational Dynamics and the Expression of Aggression and Comforting between Siblings." Journal of Language and Social Psychology 31(1):49-74.

Hartup, Willard W., and Brett Laursen. 1993. "Conflict and Context in Peer Relations." In Children on Playgrounds: Research Perspectives and Applications, edited by Craig H. Hart, 44-48. New York NY: Albans.

Hartup, Willard W., Brett Laursen, Mark I. Stewart, and Amy Eastenson. 1998. "Conflict and Friendship Relations of Young Children." Child Development 59(6):1590-1600.

Hester, Stephen, and Sally Hester. 2010. "Conversational Actions and Category Relations: An Analysis of a Children's Argument." Discourse Studies 12(1):33-48.

Honess, Terry M., Elizabeth A. Charman, Bruna Zani, Elvira Cicognani, M. Lucia Xerri, Sandy E. Jackson, and Harke A. Bosma. 1997. "Conflict between Parents and Adolescents: Variation by Family Constitution." British Journal of Developmental Psychology 15(3):367-385.

Kendall, Shari. (2008). "The Balancing Act: Framing Gendered Parental Identities at Dinnertime." Language in Society 37(4):539-568.

Kyratzis, Amy, and Guo, Jiansheng. 2001. "Preschool Girls' and Boys' Verbal Conflict Strategies in the United States and China." Research on Language and Social Interaction 34(1):45-74.

Larson, Reed W., Kathryn R. Branscomb, and Angela R. Wiley. 2006. "Forms and Functions of Family Mealtimes: Multidisciplinary Perspectives." New Directions for Child and Adolescent Development 111:1-15.

Laurier, Eric, and Sally Wiggins. 2011. "Finishing the Family Meal. The Interactional Organisation of Satiety." Appetite 56(1):53-64.

Liberati, Vivian, and Francesco Arcidiacono. 2005. "Voci in Conflitto: L'uso di Voci Diverse nelle Dispute tra Genitori e Figli." Rivista di Psicolinguistica Applicata/Journal of Applied Psycholinguistics 5(1-2):87-108.

MacWhinney, Brian. 2000. The Child Project: Computational Tools for Analyzing Talk. Pittsburgh PA: Routledge.

Muntigl, Peter, and William Turnbull. 1998. "Conversational Structure and Facework in Arguing." Journal of Pragmatics 29(3):225-256.

Nelson, Christian K. 2001. "If It Sounds Too Good To Be True, It Is: A Wittgensteinian Approach to the Conflict Literature. Language \& Communication 21(1):1-22.

Norrick, Neal R. 2013. "Aggression in Conversational Storytelling Performance." Journal of Language Aggression and Conflict 1(1):9-36.

Ochs, Elinor, and Tamar Kremer-Sadlik. 2013. Fast-Forward Family. Home, Work, and Relationships in Middle-Class America. Berkeley CA: University of California Press.

Ochs, Elinor, Clotilde Pontecorvo, and Alessandra Fasulo. 1996. "Socializing Taste." Ethnos 61(1-2):746.

Ochs, Elinor, and Bambi B. Schieffelin. 2011. "The Theory of Language Socialization." In The Handbook of Language Socialization, edited by Alessandro Duranti, Elinor Ochs and Bambi B. Schieffelin, 1-21. Malden MA: Wiley-Blackwell.

Ochs, Elinor, and Meray Shohet. 2006. "The Cultural Structuring of Mealtime Socialization.” In Family Mealtime as a Context of Development and Socialization, edited by Reed W. Larson, Angela R. Wiley and Kathryn R. Branscomb, 35-50. San Francisco CA: Jossey-Bass.

Ochs, Elinor, and Carolyn Taylor. 1992. "Science at Dinner." In Text and Context: Cross-Disciplinary Perspectives on Language Study, edited by Claire J. Kramsch and Sally McConnell-Ginet, 29-45. Lexington MA: D.C. Heath. 
Pan, Barbara A., Rivka Y. Perlmann, and Catherine E. Snow. 2000. "Food for Thought: Dinner Table as a Context for Observing Parent-Child Discourse." In Methods for studying language production, Lise Menn and Nan B. Ratner, 205-224. Mahwah NJ: Erlbaum.

Pontecorvo, Clotilde. 1987. "Discussing for Reasoning: the Role of Argument in Knowledge Construction." In Learning and Instruction, edited by Erik De Corte, Hans G. Lodewijks, Richard J. Parmentier and Pieter Span, 71-82. Oxford: Pergamon Press.

Pontecorvo, Clotilde, and Francesco Arcidiacono. 2007. Famiglie all'Italiana. Parlare a Tavola. Milan: Cortina.

Pontecorvo, Clotilde, and Francesco Arcidiacono. 2010. "Development of Reasoning Through Arguing in Young Children.” Культурно-Историческая Психология / Cultural-Historical Psychology 4:1929.

Pontecorvo, Clotilde, and Alessandra Fasulo. 1997. "Learning to Argue in Family Shared Discourse: The Reconstruction of Past Events." In Discourse, Tools and Reasoning: Essays on Situated Cognition, edited by Lauren B. Resnick, Roger Saljo, Clotilde Pontecorvo and Barbara Burge, 406-442. New York NY: Springer.

Pontecorvo, Clotilde, Alessandra Fasulo, and Laura Sterponi. 2001. "Mutual Apprentices: Making of Parenthood and Childhood in Family Dinner Conversations." Human Development 44(6):340-361.

Rigotti, Eddo, and Sara Greco Morasso. 2010. "Comparing the Argumentum Model of Topics to Other Contemporary Approaches to Argument Schemes: The Procedural and Material Components." Argumentation 24(4):489-512.

Shantz, Carolyn U., and Willard W. Hartup. 1992. Conflict in Child and Adolescent Development. Cambridge: Cambridge University Press.

Slomkowski, Cheryl L., and Judy Dunn. 1992. "Arguments and Relationships within the Family: Differences in Young Children's Disputes with Mother and Sibling." Developmental Psychology 28(5):919-924.

Tannen, Deborah. 2006. "Intertextuality in Interaction: Reframing Family Arguments in Public and Private." Text \& Talk 26(4-5):597-617.

Wiggins, Sally. 2002. "Talking with Your Mouth Full: Gustatory Mmms and the Embodiment of Pleasure." Research on Language and Social Interaction 35(3):311-336.

Wiggins, Sally. 2004. "Talking about Taste: Using a Discursive Psychological Approach to Examine Challenges to Food Evaluations." Appetite 43(1):29-38.

Wiggins, Sally. 2013. "The Social Life of 'Eugh': Disgust as Assessment in Family Mealtimes." British Journal of Social Psychology 52(3):489-509.

Wiggins, Sally, and Jonathan Potter. 2003. "Attitudes and Evaluative Practices: Category vs. Item and Subjective vs. Objective Constructions in Everyday Food Assessments." British Journal of Social Psychology 42(4):513-531.

\section{Appendix: Transcription conventions}

* indicates the speaker's turn

[...] not-transcribed segment of talking

(( )) segments added by the transcriber in order to clarify some elements of the situation

[=! ] segments added by the transcriber to indicate some paralinguistic features

xxx inaudible utterance(s)

\%act: description of speaker's actions

\%sit: description of the situation/setting

$\begin{array}{ll}, & \text { continuing intonation } \\ : & \text { falling intonation } \\ ? & \text { prolonging of sounds } \\ ! & \text { rising intonation } \\ \rightarrow & \text { exclamatory intonation } \\ & \text { maintaining the turn of talking by the } \\ \text { \% pau: } & \text { 2peaker } \\ \text { @End } & \text { end of the family meal }\end{array}$


Pre-print copy of the article:

Bova, A., \& Arcidiacono, F. (2015). Beyond Conflicts: Origin and Types of Issues Leading to Argumentative Discussions during Family Mealtimes. Journal of Language Aggression and Conflict, 3(2).

\section{Figures}

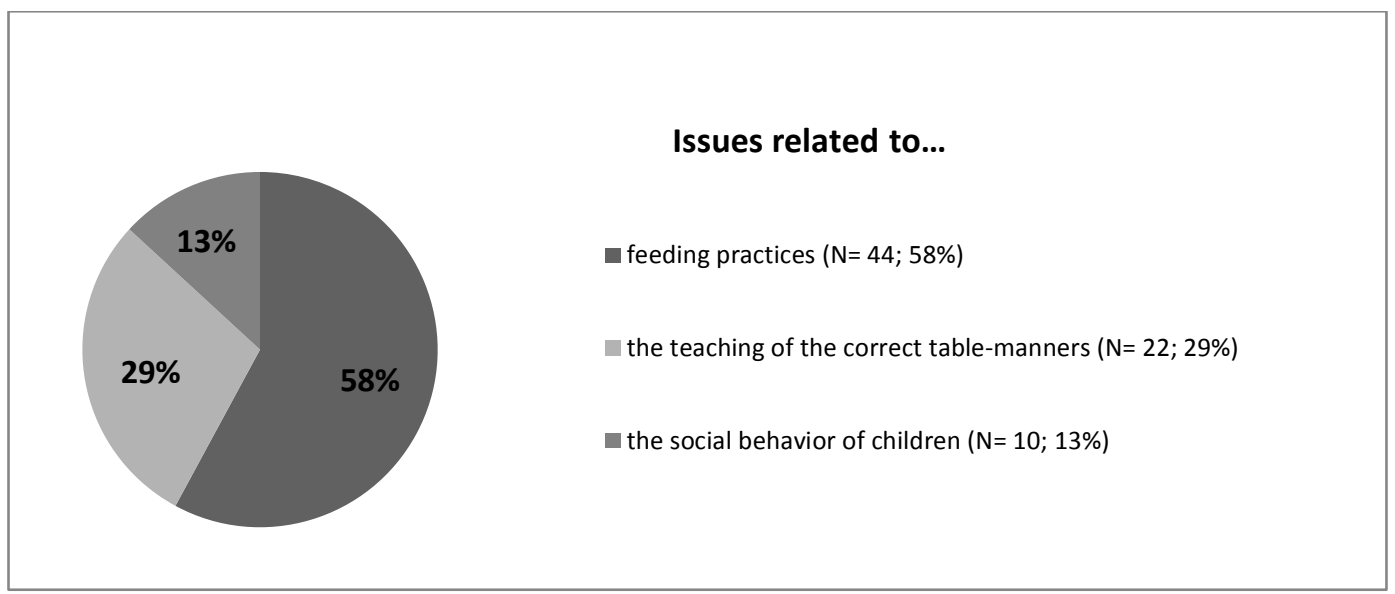

Figure 1: Types of issues generated by parental prescriptions.

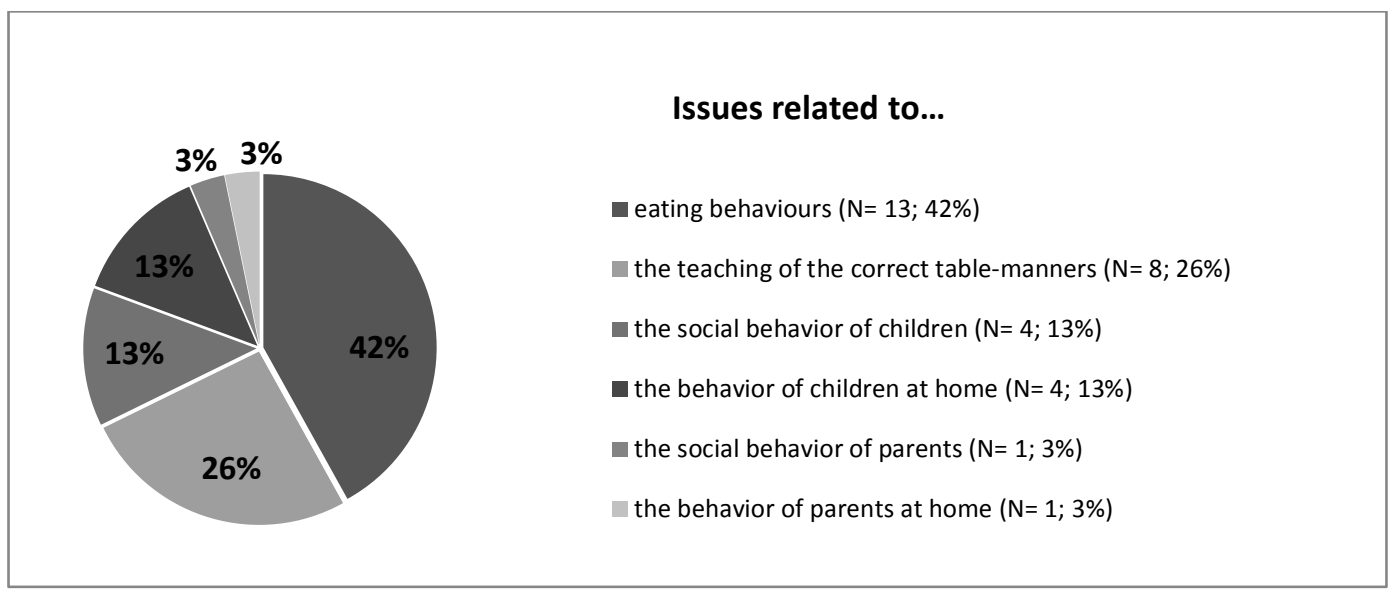

Figure 2: Types of issues generated by children's requests. 